\title{
REEXAMINANDO A CURVA DE KUZNETS: EVIDÊNCIAS PARA O BRASIL NO PERÍODO DE 1981-2009
}

\author{
REEXAMINING THE KUZNETS CURVE: EVIDENCE FOR \\ BRAZIL IN THE PERIOD 1981-2009 \\ Francisco José Silva Tabosa \\ Universidade Federal do Ceará - Fortaleza - CE - Brasil \\ Jair do Amaral Filho \\ Universidade Federal do Ceará - Fortaleza - CE - Brasil \\ Uyara de Salles Gomide \\ Universidade Federal do Ceará - Fortaleza - CE - Brasil
}

\begin{abstract}
Resumo: O presente trabalho investigou a hipótese da Curva de Kuznets com o intuito de verificar se existe uma relação de "U invertido" entre a desigualdade de renda e crescimento econômico no Brasil no período de 1981 a 2009. Por meio da econometria de dados em painel (efeitos fixos, efeitos aleatórios e primeira diferença) e com a utilização da forma linear da renda domiciliar per capita média, como medida de crescimento econômico, e dos indicadores de Gini e Theil, para a mensuração da desigualdade de renda, foram estimados dois modelos: a forma quadrática usual de Ahluwalia (1976 b) e uma modificação da forma cúbica, de List e Gallet (1999). Para uma melhor compreensão acerca do vínculo entre essas duas variáveis, a análise foi subdividida em três períodos. As evidências empíricas revelaram, de uma forma geral, que a hipótese de Kuznets não é corroborada. A partir de uma análise teórica sobre o contexto político, econômico e social vivenciado pelo Brasil na contemporaneidade, acredita-se que políticas públicas efetivas que ofereçam serviços sociais básicos de qualidade são fundamentais para que um novo ciclo de ascensão da desigualdade não se verifique.
\end{abstract}

Palavras-chave: Curva de Kuznets. Crescimento Econômico. Desigualdade de Renda. Dados em Painel.

Abstract: The present study investigated the hypothesis of the Kuznets Curve in order to check if there is a "U Inverted" relationship between the income inequality and economic growth in Brazil in the period since 1981 to 2009. Through the econometrics of panel data (fixed effects, random effects and first difference), and using the linear form of average household income per capita, as a measure of economic growth, and the Gini and Theil indicators, for the measurement of income inequality, were estimated two models: the usual quadratic form, by Ahluwalia (1976 b), and a modification of the cubic form, by List and Gallet (1999). For a better understanding of 
the relationship between these two variables, the analysis was divided into three periods. Empirical evidence showed that, in general, the Kuznets hypothesis isn't corroborated. From a theoretical analysis of the political, economic and social context experienced by Brazil in contemporaneity, it is believed that effective public policies that provide quality in basic social services are essential to avoid a new cycle of rising inequality.

Keywords: Kuznets Curve. Economic Growth. Income Inequality. Panel Data.

\section{Introdução}

A reflexão acerca da relação entre crescimento econômico e desigualdade de renda é uma temática importante na história do pensamento econômico, apesar de ser, no entanto, um elemento de controvérsias. Alguns estudos, como o de Deininger e Squire (1996a, 1998), Ravallion e Chen (1997), Easterly (1999) e Dollar e Kraay (2002) aludem que o crescimento econômico não está relacionado a altos níveis de desigualdade de renda. Em contrapartida, Alesina e Rodrick (1994) e Alesina e Perotti (1996) postulam que a desigualdade de renda está relacionada com o crescimento econômico.

De acordo com Salama e Destremau (1999), até a metade da década de 1970, o crescimento econômico seguia acompanhado de aumento dos salários reais e a diferença entre os rendimentos do capital e do trabalho se reduzia. Entretanto, um aumento significativo da desigualdade e da pobreza tem sido uma tendência observada ao longo dos últimos 20 anos, seja nas sociedades desenvolvidas ou nas regiões periféricas.

O vínculo entre esses dois fenômenos, crescimento econômico e desigualdade de renda, foi muito bem relatado no trabalho de Simon Kuznets (1955). Seu insight partiu de alguns questionamentos importantes acerca do crescimento econômico: (i) A distribuição de renda aumenta ou decresce à medida que ocorre o crescimento econômico? (ii) Quais são as características e causas das mudanças de longo prazo na distribuição de renda? E ainda, (iii) quais fatores determinam os níveis seculares das desigualdades de renda?

A partir de um estudo empírico com dados em séries de tempo dos Estados Unidos (EUA), Inglaterra e Alemanha (Saxônia e Prússia), o autor encontrou uma tendência de suavização da desigualdade ao longo do tempo. Contando ainda com um exemplo numérico ilustrativo de uma economia dualista, considerando dois setores produtivos, percebeu 
que a redução da desigualdade apenas ocorre nas últimas fases do crescimento econômico dos países desenvolvidos, de forma que no início do processo de transição das atividades econômicas, do setor tradicional, agrícola, para o setor mais produtivo e rentável, industrial, a desigualdade tenderia a se elevar.

Baseando-se na observação das mudanças estruturais da economia, justifica que iniciado o período de industrialização, a concentração de renda se acentua pelo fato de: a produtividade per capita nas atividades industriais crescer mais rapidamente do que a do setor tradicional, pela ampliação do hiato entre os salários de profissionais qualificados e não qualificados, combinados ao aumento populacional, que, para Kuznets (1955), é parte causa e efeito do longo movimento da desigualdade de renda.

Kuznets (1955) afirma também que à medida que o crescimento econômico se desenrola, ocorre a disseminação dos benefícios nas sociedades democráticas, onde os sistemas de saúde e educação se tornam mais acessíveis, e a população se torna mais consciente de seus direitos e deveres políticos. Dessa forma, melhores oportunidades são oferecidas às sociedades, possibilitando o incremento da produtividade e da redução das desigualdades, amenizando os efeitos da rápida industrialização e urbanização.

Como consequência dessa constatação, Kuznets postula a existência de uma relação não linear entre crescimento econômico e desigualdade de renda na forma de um "U invertido", indicando a dinâmica da desigualdade ao longo do tempo, em que esta inicialmente se eleva, estabiliza-se, e se reduz à medida que a economia cresce.

Visando a responder essas questões, muitos foram os estudiosos que se debruçaram sobre o tema estimulando o debate. Alhuwalia (1976 b); Amos (1988); Acemoglu e Robinson (2002); Anand e Kanbur (1993 a); List e Gallet (1999); Bagolin, Gabe e Ribeiro (2004); Bêrni, Marquetti e Kloeckner (2002); Salvato et al (2006) e Jacinto e Tejada (2004); Barros e Gomes (2008); Linhares et al (2012) e Taques e Mazzuti (2010) são uma pequena amostra do que vem sendo escrito ao longo dos anos.

No entanto, mal se avista um consenso sobre a existência de tal padronização na relação entre crescimento e desigualdade. Por se basearem em amostras, variáveis e metodologias diferentes, os resultados encontrados dificilmente convergem para uma conclusão 
definitiva.

Empregando a hipótese da Curva de Kuznets como parâmetro teórico, o presente trabalho tem como objetivo central verificar de que forma o crescimento econômico e a desigualdade de renda no Brasil se relacionaram ao longo dos anos de 1981 a 2009, a partir de um modelo econométrico para dados em painel. Portanto, propõe-se aqui a análise de um período relativamente amplo, que engloba diferentes contextos da economia brasileira, a partir do desenvolvimento de dois modelos de regressões, considerando dois índices de concentração de renda, para diferentes períodos, visando à observação da influência dos diversos contextos sobre as variáveis consideradas.

Dessa forma, este estudo, além desta introdução, estrutura-se por mais cinco capítulos. No próximo, será apresentado o referencial teórico e empírico que fundamenta a problematização aqui proposta, contando com o artigo de Kuznets (1955) e a revisão de literatura produzida sobre esta temática. Em seguida, o capítulo três descreve a metodologia utilizada no estudo e faz uma descrição da base de dados acompanhada de uma análise descritiva destas informações. O capítulo seguinte expõe as evidências obtidas a partir da análise empírica. No último capítulo, reservado às considerações finais do trabalho, discute-se os resultados à luz do momento histórico vivenciado pelo Brasil no período em questão.

\section{Crescimento e Desigualdade: a hipótese de Kuznets}

Kuznets (1955) busca analisar e compreender o comportamento da desigualdade ao longo das diferentes fases do crescimento econômico. O fundamento que ganhou maior notoriedade entre os desenvolvimentistas foi batizado posteriormente por Anand e Kanbur (1993 a) como "O Processo de Kuznets", mecanismo bem definido em que a população migra do setor agrícola (rural, tradicional) para o não agrícola (moderno, urbano). Tal transição, descrita pelo autor, foi uma adaptação do artigo publicado por Lewis (1954) sobre o modelo de desenvolvimento dualista, que apresentava a lógica da transição populacional, posteriormente trazida para a esfera da distribuição de renda por Kuznets. 
Como o próprio autor ressalta, a relação entre crescimento e desigualdade, mais conhecida como a hipótese de $U$ invertido de Kuznets, é o resultado de um trabalho baseado em $5 \%$ de informações empíricas e 95\% de especulações (KUZNETS, 1955, p. 26).

A proposta desenvolvida por Kuznets parece ter inspirado muitos pesquisadores em estudar a relação associativa entre o nível de crescimento econômico e a desigualdade de renda. Na literatura internacional, pode-se citar: Ahluwalia (1976 b); Amos (1988); Acemoglu e Robinson (2002); Anand e Kanbur (1993 a); Bourguignon e Morrison (1990); Campano e Salvatore (1988); List e Gallet (1999); Milanovic (1995); Papanek e Kyn (1986); Ravallion (1995); Tribble (1996).

Conforme Ahluwalia (1976 a), tais relações são mais bem descritas como "fatos estilizados", que podem ser observados, mas, no entanto, necessitam de formulações teóricas para explicá-las. Dessa forma, não há um modelo teórico estabelecido que sugira um conjunto de regressores que devam ser incluídos no modelo, entretanto, verificase entre os estudos que a forma funcional mais usual é o polinômio de $2^{\circ}$ grau.

Diversas abordagens econométricas foram empregadas com o fim de se testar a hipótese do $U$ invertido. A motivação pelo uso de distintas metodologias se deve ao emprego de diferentes bases de dados e às limitações dos métodos empregados. Pode-se testar a hipótese do $\mathrm{U}$ invertido acompanhando um dado país ou região individual ao longo do tempo, por meio da metodologia de séries de tempo; comparando diferentes países ou regiões em um determinado período, utilizando dados em cortes transversais; ou então, quando os dados são disponíveis, observá-los ao longo do tempo, adotando dados em painel.

Segundo Ahluwalia (1976 b), a verdadeira relação entre desigualdade e desenvolvimento é complexa, já que vários processos de mudança estrutural são correlacionados com a desigualdade de renda. Para ele, deve-se estar atento à natureza particular do crescimento nos diferentes países e suas implicações na desigualdade, atendo-se a uma análise profunda sobre a experiência histórica de cada país.

Kanbur (2012) ressalta ainda que a permanência de instituições sociais e econômicas rígidas nos países subdesenvolvidos, identificadas com antigos padrões de valores, acarretaria, como consequência do 
processo de industrialização, efeitos mais cruéis aos indivíduos mais pobres ao invés de criar novas oportunidades para os mesmos.

Acemoglu e Robinson (2002) propõem uma teoria políticaeconômica para a curva de Kuznets, em que fatores políticos e transformações institucionais são cruciais para entender os padrões de desigualdade, de forma que o declínio observado da desigualdade ao longo do crescimento é derivado de reformas políticas e seus impactos subsequentes. Tais transformações, induzidas pela ascensão das tensões sociais e instabilidades políticas, aumentariam de acordo com a elevação da desigualdade à medida que o processo de industrialização se desenvolve.

Nessa perspectiva, os autores argumentam que o declínio na desigualdade dos países europeus ao longo do século XIX não foi uma mera consequência do desenrolar do processo econômico, mas também o resultado da mobilização das massas populacionais, insatisfeitas com os resultados do processo de industrialização, que levaram a mudanças políticas e institucionais favoráveis à redistribuição de renda e à redução das disparidades.

Duas décadas após o lançamento do célebre artigo de Kuznets (1955), Ahluwalia (1976 b) publica seu estudo acerca da aplicabilidade da hipótese do $U$ invertido para países em desenvolvimento. Com uma amostra de 60 países, incluindo 40 em estado de desenvolvimento, 14 desenvolvidos e 6 socialistas, a estimação central de seu trabalho testa o relacionamento log-quadrático entre desigualdade e renda per capita em dados de corte transversal para a amostra completa de 60 países, como também para somente os 40 países em processo de desenvolvimento.

Seus resultados apresentam fortes evidências da existência da hipótese de Kuznets, em que a desigualdade relativa cresce substancialmente nos primeiros estágios do processo de desenvolvimento, revertendo tal tendência nos últimos. Indicaram ainda que o ponto de reversão dessa tendência é mais prolongado para os grupos mais pobres, desprovidos de oportunidades.

O artigo refuta a ideia de Adelman e Morris (1973) em que países em desenvolvimento sofrem não apenas com o aumento da desigualdade, mas também com o empobrecimento absoluto de grande parte da população no curso do desenvolvimento econômico. O autor 
mostra que os rendimentos médios dos grupos mais pobres crescem com a elevação do Produto Interno Bruto - PIB per capita, entretanto, mais lentamente do que os rendimentos dos grupos de renda mais alta e, que crescimento mais acelerado não está sistematicamente associado com maior nível de desigualdade. Dessa forma, Ahluwalia foi um dos defensores da adoção de uma postura não intervencionista por parte do governo. Seus resultados foram importantes para justificar políticas desse caráter.

Uma extensão deste trabalho se direcionou para a aplicação das formas funcionais derivadas aos dados de Ahluwalia (1976 b) para o conjunto total dos 60 países e também para os 40 países em processo de desenvolvimento. Os resultados, que divergem para cada amostra empregada, assim como para cada forma funcional e índice adotado, não apoiaram a existência da hipótese de Kuznets para os países considerados. Os autores enfatizam que, com a utilização de dados em cortes transversais, testa-se a hipótese de que todos os países seguem o mesmo processo de Kuznets. Sem a disponibilidade de dados em série de tempo, a rejeição dessa hipótese deixa em aberto a possibilidade de que cada país possua seu próprio processo de Kuznets; que existam relações diferenciadas entre desigualdade e desenvolvimento para cada unidade do corte transversal; ou ainda, que tal processo não ocorra em alguns casos.

Os métodos de corte transversal e séries de tempo foram vastamente utilizados nas décadas subsequentes ao artigo de Kuznets com a finalidade de se estimar a curva de $U$ invertido. Contudo, tais métodos foram muito criticados por suas limitações intrínsecas, descritas a seguir. Em meio a isso, o emprego de estimativas em dados em painel tem sido cada vez mais recorrente, pois apresentam resultados mais significantes.

Para Tribble (1996), a mesma sequência de fatos que leva à ampliação das desigualdades durante o processo de industrialização, também ocorre durante a ampliação do setor terciário, ou seja, o nível agregado da desigualdade cresce à medida que ocorre a transição demográfica da força de trabalho. O autor reconceitua o processo de Kuznets de um $U$ invertido para uma curva em $\mathrm{S}$, sendo modelada a partir de uma função cúbica, ao invés de quadrática. Amos (1988) também sugere que, depois de finalizado o processo de Kuznets, a 
desigualdade de renda regional tende novamente a crescer ao invés de se manter constante, gestando uma nova curva ascendente, caracterizando uma parábola cúbica.

Vale ressaltar que a existência da relação cúbica não necessariamente invalida a proposta de Kuznets. Como argumentado anteriormente, em uma economia com diversos setores, é possível que a relação crescimento-desigualdade se reverta em função do surgimento de um setor mais novo e atrativo, de forma a elevar a desigualdade novamente. Assim, o surgimento dos setores de alta tecnologia, intensivos em capital humano especializado, a expansão do setor de serviços e o enfraquecimento do Estado, poderiam ser responsáveis pela finalização da fase decrescente e o início de uma nova fase de crescimento na desigualdade, sobretudo em países industrializados.

Considerando a intuição que permeia a formulação da hipótese de Kuznets, pode-se dizer que os ciclos de progresso tecnológico desempenham um papel significativo na evolução da desigualdade de rendimentos e da mobilidade salarial intergeracional, de forma que os ganhos podem governar o ritmo do progresso tecnológico, assim como do próprio crescimento econômico (GALOR E TSIDDON, 1997).

O Quadro 1 apresenta um sumário de alguns estudos encontrados na literatura internacional sobre o tema, contendo o método, os dados utilizados, período analisado e resultados obtidos.

Quadro 1. Evidências empíricas para a hipótese de Kuznets no mundo

\begin{tabular}{|c|c|c|c|c|c|}
\hline Autor & Método & Variáveis & Período & Nível de Análise & Resultados \\
\hline $\begin{array}{c}\text { Ahluwalia } \\
(1976 b)\end{array}$ & $\begin{array}{l}\text { Corte transversal. } \\
\text { Estimações com a } \\
\text { amostra completa e } \\
\text { com os } 40 \text { países } \\
\text { em } \\
\text { desenvolvimento. } \\
\text { Polinômio de } \\
\text { segundo grau com } \\
\text { inclusão de } \\
\text { dummies para } \\
\text { países socialistas. }\end{array}$ & $\begin{array}{l}\text { Parcela de renda } \\
\text { dos diferentes } \\
\text { grupos percentis } \\
\text { como variável de } \\
\text { desigualdade e o } \\
\text { logaritmo do } \\
\text { PNB per capita. }\end{array}$ & 1976 & $\begin{array}{c}\text { Amostra de } 60 \\
\text { países ( } 40 \\
\text { subdesenvolvidos, } \\
14 \text { desenvolvidos } \\
\text { e } 6 \text { socialistas) }\end{array}$ & $\begin{array}{c}\text { Corrobora o U } \\
\text { invertido }\end{array}$ \\
\hline $\begin{array}{l}\text { Anand e } \\
\text { Kanbur } \\
\text { (1993a) }\end{array}$ & $\begin{array}{l}\text { Corte transversal. } \\
\text { Estimação de } \\
\text { formas funcionais } \\
\text { adequadas para } \\
\text { seis medidas de } \\
\text { desigualdade. }\end{array}$ & $\begin{array}{l}\text { PIB per capita em } \\
\text { função de seis } \\
\text { medidas de } \\
\text { desigualdade. }\end{array}$ & $\begin{array}{c}\text { Dados de } \\
\text { Ahluwalia } \\
\text { (1976) }\end{array}$ & $\begin{array}{c}\text { Amostra de } 60 \\
\text { países ( } 40 \\
\text { subdesenvolvidos, } \\
14 \text { desenvolvidos } \\
\text { e } 6 \text { socialistas) }\end{array}$ & $\begin{array}{l}\text { Disparidade nos } \\
\text { resultados para } \\
\text { cada forma } \\
\text { funcional e índice } \\
\text { empregado, não } \\
\text { apoiando a } \\
\text { hipótese de U } \\
\text { invertido. }\end{array}$ \\
\hline
\end{tabular}




\begin{tabular}{|c|c|c|c|c|c|}
\hline $\begin{array}{l}\text { Ravallion } \\
\text { (1995) }\end{array}$ & $\begin{array}{l}\text { Dados em painel. } \\
\text { Índice de Gini em } \\
\text { função do consumo } \\
\text { médio per capita. }\end{array}$ & $\begin{array}{l}\text { Índice de Gini e } \\
\text { consumo médio } \\
\text { per capita. }\end{array}$ & $\begin{array}{l}\text { Dados da } \\
\text { década } \\
\text { de } 1980 .\end{array}$ & $\begin{array}{c}\text { Amostra de } 36 \\
\text { países }\end{array}$ & $\begin{array}{l}\text { Corrobora o U } \\
\text { invertido, mas não } \\
\text { revelou } \\
\text { significância } \\
\text { estatística. }\end{array}$ \\
\hline $\begin{array}{l}\text { Deininger } \\
\text { e Squire } \\
\text { (1998) }\end{array}$ & $\begin{array}{c}\text { Dados em corte } \\
\text { transversal. } \\
\text { Índice de Gini em } \\
\text { função da renda per } \\
\text { capita. }\end{array}$ & $\begin{array}{l}\text { Índice de Gini e } \\
\text { renda per capita }\end{array}$ & $\begin{array}{c}1960 \mathrm{a} \\
1990\end{array}$ & $\begin{array}{c}\text { Amostra de } 108 \\
\text { países } \\
\text { desenvolvidos e } \\
\text { em estado de } \\
\text { desenvolvimento. }\end{array}$ & $\begin{array}{c}\text { Os dados não } \\
\text { apóiam a hipótese } \\
\text { de Kuznets. }\end{array}$ \\
\hline $\begin{array}{l}\text { List e } \\
\text { Gallet } \\
\text { (1999) }\end{array}$ & $\begin{array}{l}\text { Painel não } \\
\text { balanceado. } \\
\text { Polinômio de } \\
\text { terceiro grau. }\end{array}$ & $\begin{array}{l}\text { Índice de Gini } \\
\text { em função da } \\
\text { renda per capita. }\end{array}$ & $\begin{array}{l}1961 \text { a } \\
19992\end{array}$ & $\begin{array}{c}\text { Amostra de } 71 \\
\text { países }\end{array}$ & $\begin{array}{c}\text { Corrobora o U } \\
\text { invertido para } \\
\text { países pouco } \\
\text { desenvolvidos, } \\
\text { enquanto que, em } \\
\text { países avançados, } \\
\text { a relação entre } \\
\text { desigualdade e } \\
\text { renda torna-se } \\
\text { positiva } \\
\text { novamente. }\end{array}$ \\
\hline $\begin{array}{l}\text { Daudelin e } \\
\text { Samy } \\
(2011)\end{array}$ & $\begin{array}{l}\text { Dados em corte } \\
\text { transversal. } \\
\text { Índice de Gini em } \\
\text { função da renda per } \\
\text { capita, renda per } \\
\text { capita ao quadrado } \\
\text { e demais variáveis } \\
\text { (regressores em } \\
\text { logaritmos). }\end{array}$ & $\begin{array}{c}\text { Índice de Gini, } \\
\text { renda per capita, } \\
\text { taxa de } \\
\text { urbanização, } \\
\text { taxa de } \\
\text { escolaridade e } \\
\text { transferências } \\
\text { governamentais.. }\end{array}$ & $\begin{array}{l}\text { Dados } \\
\text { dos } \\
\text { censos } \\
\text { de } 1991 \\
\text { e } 2000 .\end{array}$ & $\begin{array}{c}\text { Amostra de mais } \\
\text { de } 5000 \\
\text { municípios } \\
\text { brasileiros }\end{array}$ & $\begin{array}{c}\text { Existência de U } \\
\text { invertido no ano } \\
\text { de } 1991, \text { mas } \\
\text { verificação de um } \\
\text { U normal no ano } \\
\text { de } 2000, \\
\text { indicando possível } \\
\text { processo de } \\
\text { desindustrialização }\end{array}$ \\
\hline
\end{tabular}

Fonte: Dados da pesquisa. Elaboração dos autores.

A busca pela compreensão da imbricada relação entre desigualdade de renda e crescimento também se faz presente no Brasil. Dentre estes estudos Bagolin, Gabe e Ribeiro (2004); Bêrni, Marquetti e Kloeckner (2002); Salvato et al (2006) e Jacinto e Tejada (2004) não rejeitam a hipótese do $U$ invertido. Enquanto, Barros e Gomes (2008); Linhares et al (2012) e Taques e Mazzuti (2010) apontam para a existência de limitações da aplicabilidade da curva de Kuznets para explicar o processo de evolução da desigualdade no Brasil.

Salvato et al (2006) testaram a validade da hipótese de Kuznets em Minas Gerais. Estimaram a forma quadrática padrão utilizando a metodologia de cortes transversais e de dados em painel, utilizando os índices de Gini e $\mathrm{L}$ de Theil, além da renda per capita municipal nos anos de 1991 e 2000. Comparando os resultados obtidos, elegeram o modelo de efeitos fixos como a melhor estimativa, em que a trajetória da desigualdade tem a forma de $U$ invertido. Portanto, sugerem que os 
municípios mineiros não possuem trajetórias semelhantes de desenvolvimento econômico.

Taques e Mazzutti (2010) desenvolveram sua pesquisa sobre todas as unidades federativas brasileiras, incluindo o Distrito Federal, no período entre 1995 a 2008. Testaram a robustez das estimativas adotando dois índices de desigualdade de renda (índice de Gini e L de Theil), empregando o logaritmo natural destes índices e, ainda, classificando os estados entre Índice de Desenvolvimento Humano - IDH médio e alto, para maior precisão nos modelos. Utilizaram dados em painel - cortes transversais agregados (POLS), efeito fixo (EF), efeito aleatório (EA) e primeira diferença (PD). Os resultados obtidos indicaram a falha nos testes de robustez devido à sensibilidade ao indicador de desigualdade utilizado, assim como ao método econométrico empregado, não evidenciando a hipótese de Kuznets para o Brasil.

Barros e Gomes (2008) também investigaram a validade da hipótese de Kuznets para o Brasil nos anos de 1991 e 2000 utilizando o método de dados em painel (POLS, EF e EA). Empregaram os índices de Gini e L de Theil como proxy da desigualdade, e, como medidas de crescimento, a renda per capita e a razão entre a população urbana e a população total. Estimando diversas formas funcionais, encontraram pouca evidência a favor desse padrão de desigualdade no país. As estimações para o polinômio de segundo grau e forma funcional de Anand e Kanbur (1993) não rejeitam a hipótese, mas apresentaram baixo poder explicativo, enquanto que, a forma funcional proposta por List e Gallet (1999), polinômio do terceiro grau, apenas é confirmada quando se usa o índice de Gini com a variável urbana. Contudo, uma importante contribuição dos autores foi utilização da razão entre a população urbana e total sendo esta uma nova variável favorável ao estudo da temática

Bagolin, Gabe e Ribeiro (2004) investigaram a relação crescimento e desigualdade no Rio Grande do Sul entre os anos de 1970 e 1991. Segundo os autores, neste período o estado vivenciou um crescimento de quase $25 \%$ na renda per capita, entretanto, este processo veio acompanhado de um aumento na desigualdade de renda, sobretudo intramunicipal. Empregando a estimação em cortes transversais e em dados em painel, encontraram que o termo de erro aleatório não é exógeno ao modelo de forma que as estimativas de efeitos fixos são 
não viesadas e sugerem que, apesar de cada município ter uma relação específica entre desigualdade-crescimento, a curva de Kuznets é válida para descrever a evolução da desigualdade nos municípios do RS.

Ainda para o Rio Grande do Sul, Bêrni, Marquetti e Kloeckner (2002) também pesquisaram a relação entre desigualdade de renda em 1991 e o nível de renda per capita em 1990 nos municípios do estado. Utilizando uma abordagem não paramétrica, chamada regressão local, consideraram setores distintos da economia gaúcha para a estimação da curva de Kuznets (ou Williamson-Kuznets) utilizando o valor adicionado bruto per capita setorial. Os autores não rejeitam a hipótese de Kuznets, mas sugerem cautela em sua aceitação. No caso do setor agropecuário, de baixa produtividade, não se observou o padrão $U$ invertido, enquanto para os setores industrial e de serviços a hipótese não pode ser descartada.

Linhares et a/ (2012) utilizaram um painel de dados contendo 21 estados do Brasil, entre os anos de 1986 a 2005. Estimando um modelo não linear com efeito threshold mostraram que a relação entre desigualdade e renda se diferencia de acordo com o estágio de desenvolvimento de cada estado. Desta forma, o padrão de $U$ invertido apenas é verificado nas economias com renda per capita acima de R\$ 258,00. Enfatizam que políticas de crescimento econômico deveriam ser mais bem direcionadas a cada perfil socioeconômico regional, pois estas não necessariamente implicam na melhoria da distribuição de renda nos estados como um todo. Os autores ressaltam que para os estados com renda per capita abaixo de $R \$ 258,00$, investimentos em capital humano é a política mais indicada para a mitigação dos níveis de desigualdade de renda, enquanto que, para estados com valores superiores a este se deve, além de se investir em capital humano, estimular o crescimento do PIB per capita.

No Nordeste brasileiro, o crescimento nas décadas de 1970 e 1980 foi superior à média nacional. Considerando que a relação entre desigualdade e desenvolvimento proposta por Kuznets possa ser estendida para essa região, Jacinto e Tejada (2004) investigaram a possibilidade da existência da curva de $U$ invertido nessa região. As formas funcionais empregadas foram o polinômio de $2^{\circ}$ grau e um modelo proposto por Anand e Kanbur (1993), a partir de dados em cortes transversais e em painel. Utilizaram o índice $L$ de Theil e renda 
per capita para o período que compreende os anos de 1970 a 1991. Nos dois casos, a hipótese de U invertido não foi rejeitada.

No Quadro 2, segue uma breve revisão dos artigos desenvolvidos sobre a hipótese de Kuznets no Brasil, citados neste trabalho. 


\section{Quadro 2. Evidências empíricas para a hipótese de Kuznets no Brasil}

\begin{tabular}{|c|c|c|c|c|c|}
\hline Autor & Método & Variáveis & Período & $\begin{array}{l}\text { Nível de } \\
\text { Análise }\end{array}$ & Resultados \\
\hline $\begin{array}{l}\text { Bêrni, Marquetti e } \\
\text { Kloeckner (2002) }\end{array}$ & $\begin{array}{l}\text { Corte transversal, } \\
\text { modelo não } \\
\text { paramétrico } \\
\text { (regressão local) }\end{array}$ & $\begin{array}{l}\text { Índice de Theil, } \\
\text { valor adicionado } \\
\text { bruto, renda per } \\
\text { capita setorial, } \\
\text { densidade } \\
\text { demográfica } \\
\text { municipal }\end{array}$ & $\begin{array}{l}1990 \text { e } \\
1991 .\end{array}$ & $\begin{array}{l}\text { Municípios } \\
\text { do Rio } \\
\text { Grande do } \\
\text { Sul. }\end{array}$ & $\begin{array}{c}\text { Confirma o U } \\
\text { invertido } \\
\text { quando a } \\
\text { densidade } \\
\text { demográfica } \\
\text { municipal ou } \\
\text { a renda } \\
\text { municipal } \\
\text { são incluídos } \\
\text { no modelo. }\end{array}$ \\
\hline $\begin{array}{c}\text { Jacinto e Tejada } \\
\qquad(2004)\end{array}$ & $\begin{array}{l}\text { Cortes transversais } \\
\text { e dados em painel. } \\
\text { Modelos propostos } \\
\text { por Ahluwalia } \\
\text { (1976 a) e Anand e } \\
\text { Kanbur (1933 a). }\end{array}$ & $\begin{array}{l}\text { Índice de Theil e } \\
\text { renda per capita. }\end{array}$ & $\begin{array}{c}1970 \\
1980 \text { e } \\
1991\end{array}$ & $\begin{array}{l}\text { Municípios } \\
\text { da região } \\
\text { nordeste. }\end{array}$ & $\begin{array}{c}\text { Não rejeição } \\
\text { da existência } \\
\text { da curva de } \\
\text { Kuznets } \\
\text { pelos dois } \\
\text { métodos e } \\
\text { formas } \\
\text { funcionais. }\end{array}$ \\
\hline $\begin{array}{l}\text { Barros e Gomes } \\
\qquad(2008)\end{array}$ & $\begin{array}{l}\text { Dados em painel } \\
\text { (POLS, EF e EA). } \\
\text { Variações da forma } \\
\text { polinomial de } 2^{\circ} \text { e } \\
3^{\circ} \text { grau e dois } \\
\text { modelos de Anand } \\
\text { e Kanbur (1993). }\end{array}$ & $\begin{array}{l}\text { Índices de Gini e L } \\
\text { de Theil, renda per } \\
\text { capita e fração da } \\
\text { população urbana. }\end{array}$ & $\begin{array}{l}1991 \mathrm{a} \\
2000\end{array}$ & $\begin{array}{l}\text { Municípios } \\
\text { brasileiros }\end{array}$ & $\begin{array}{c}\text { Resultados } \\
\text { ambíguos. } \\
\text { Pouca } \\
\text { evidência do } \\
\text { padrão U } \\
\text { invertido. }\end{array}$ \\
\hline $\begin{array}{c}\text { Taques e Mazzuti } \\
(2010)\end{array}$ & $\begin{array}{l}\text { Dados em painel } \\
\text { (POLS, EA, EF e PD). } \\
\text { Forma quadrática } \\
\text { padrão com } \\
\text { especificações log- } \\
\text { log e semi-log. }\end{array}$ & $\begin{array}{c}\text { Índices de Gini e L } \\
\text { de Theil e renda } \\
\text { per capita }\end{array}$ & $\begin{array}{l}1995 \mathrm{a} \\
2008 .\end{array}$ & $\begin{array}{l}\text { Unidades } \\
\text { federativas. }\end{array}$ & $\begin{array}{l}\text { Não } \\
\text { verificação } \\
\text { da hipótese } \\
\text { de Kuznets. }\end{array}$ \\
\hline $\begin{array}{l}\text { Linhares et al } \\
\text { (2012) }\end{array}$ & $\begin{array}{l}\text { Painel com efeito } \\
\text { fixo não linear } \\
\text { (threshold). } \\
\text { Variações da forma } \\
\text { polinomial de } 2^{\circ} \mathrm{e} \\
3^{\circ} \text { grau com a } \\
\text { variável renda } \\
\text { linearizada. }\end{array}$ & $\begin{array}{l}\text { Índice de Gini, } \\
\text { renda domiciliar } \\
\text { per capita média, } \\
\text { anos de estudo, } \\
\text { medida de abertura } \\
\text { comercial, } \\
\text { consumo de } \\
\text { energia elétrica. }\end{array}$ & $\begin{array}{l}1986 \mathrm{a} \\
2005\end{array}$ & $\begin{array}{l}\text { Unidades } \\
\text { federativas. }\end{array}$ & $\begin{array}{c}\text { Verificação } \\
\text { da hipótese } \\
\text { de Kuznets } \\
\text { apenas nas } \\
\text { economias } \\
\text { com renda } \\
\text { per capita } \\
\text { acima de } \mathrm{R} \$ \\
258,00 .\end{array}$ \\
\hline
\end{tabular}

Fonte: Dados da pesquisa. Elaboração dos autores.

\section{$3 \quad$ METODOLOGIA}


Seguem, nesta seção, os modelos teóricos, as técnicas, assim como a base de dados empregados para avaliar a relação entre desigualdade e crescimento econômico no Brasil no período entre 1981 a 2009.

\subsection{O Modelo econométrico}

Apesar de a maioria dos trabalhos utilizarem dados em corte transversal para testar a curva de Kuznets, a aplicação de tal método acaba ignorando as diferenças históricas particulares de cada estado no curso da evolução da renda e da desigualdade. Tal omissão pode acarretar em conclusões errôneas acerca das regressões estimadas (SALVATO, 2006).

Dada a limitação citada acima, o uso de dados em painel, que incorporam séries de tempo aos dados em cortes transversais, faz-se uma alternativa interessante, sobretudo por possuir maior variabilidade dos dados, menor colinearidade entre as variáveis, maior número de graus de liberdade, maior eficiência dos estimadores e agregarem uma quantidade maior de informação.

Consideram ainda a existência de heterogeneidade entre os diferentes estados, assim como a dependência entre elas, tendo grande flexibilidade quanto à modelagem das diferenças entre as observações, solucionando os problemas relacionados às variáveis omitidas (GREENE, 2012).

Para a análise da trajetória da desigualdade no Brasil ao longo das três últimas décadas, considera-se um modelo em painel, onde a desigualdade de renda basicamente é função do crescimento econômico. As regressões estimadas podem ser descritas da seguinte forma:

Modelo 1

$$
D_{i t}=\beta_{0}+\beta_{1} Y_{i t}+\beta_{2} Y^{2}{ }_{i t}+\chi_{i}+\varepsilon_{i t}
$$

Modelo 2:

$$
D_{i t}=\beta_{0}+\beta_{1} Y_{i t}+\beta_{2} Y^{2}{ }_{i t}+\beta_{3} Y^{3}{ }_{i t}+\beta_{4} \tau+\chi_{i}+\varepsilon_{i t}
$$


Sendo $D_{i t}$ uma medida de desigualdade, no caso os índices de Gini e Theil, $Y_{i t}$ a renda domiciliar per capita média, daqui em diante renda, em sua forma linear, quadrática e cúbica, para mensurar o crescimento econômico, $\chi_{i}$ o efeito ou a heterogeneidade individual das unidades do corte transversal, e $\varepsilon_{i t}$, o erro aleatório. $O$ índice $i$ representa a unidade do corte transversal (estados brasileiros) e $t$ representa os anos no período da amostra'.

O modelo 1, muito utilizado nos trabalhos desenvolvidos sobre esta temática, é uma versão reduzida da forma funcional desenvolvida por Ahluwalia (1976), enquanto que o modelo 2 é uma modificação da estimação proposta por List e Gallet (1999), com o acréscimo de uma variável de tendência, representada por $\tau$, que tem como intuito captar mudanças estruturais significativas na economia brasileira.

Para uma melhor compreensão acerca da relação entre desigualdade e crescimento no Brasil, a análise foi subdividida em períodos. Os modelos foram estimados com as unidades federativas ${ }^{2}$ do Brasil, incluindo o Distrito Federal, durante os anos de 1981 a 2009 e os períodos pré Plano Real (1981 a 1994) e pós Plano Real (1995 a 2009).

As hipóteses para a obtenção do formato de "U invertido" para a curva estimada são as seguintes: $\beta_{1}>0, \beta_{2}<0$ para o modelo $1 \mathrm{e}$, adicionalmente, para o modelo 2 , a significância do coeficiente $\beta_{3}>0$.

As regressões dos dados em painel foram estimadas utilizando os modelos de Efeitos Fixos (EF), Efeitos Aleatórios (EA) e Primeira Diferença (PD). O objetivo dessas estimações é compará-las a fim de obter aquela que melhor capte a relação entre crescimento econômico e a desigualdade na distribuição de renda nos estados brasileiros.

Como a escolha entre os modelos de Efeitos Fixos e de Efeitos Aleatórios recai sobre a observância ou não da correlação entre as variáveis explicativas e as heterogeneidades não observadas, é importante haver um procedimento que seja capaz de examinar tal hipótese. O Teste de Hausman consiste na diferença entre as significâncias estatísticas das estimativas de EF e EA (WOOLDRIDGE, 2002).

1 Optou-se por aplicar o logaritmo neperiano em todas as variáveis de renda, de maneira que os coeficientes podem ser interpretados diretamente como elasticidades.

2 O Estado de Tocantins foi excluído da amostra devido a sua emancipação tardia, acarretando na indisponibilidade dos dados das séries no período anterior ao ano de 1992. 
Sob a hipótese nula, as diferenças nos coeficientes não são sistemáticas, de forma que a sua rejeição indica que o modelo de EF oferece estimativas mais consistentes que as do modelo de EA. ${ }^{3}$ Os testes de Hausman realizados neste trabalho encontram-se no Anexo.

\subsection{Descrição dos dados e análise descritiva}

As informações necessárias para analisar a relação entre a desigualdade de renda e o crescimento econômico foram obtidas no Instituto de Pesquisa Econômica Aplicada - IPEA e se referem a 25 estados do Brasil, além do Distrito Federal, configurando um painel balanceado, que contempla o período entre os anos de 1981 a 2009.

A renda domiciliar per capita média ${ }^{4}$ da população foi empregada como medida do nível de crescimento econômico, e os índices de Gini e de Theil 5 foram utilizados para se estudar a evolução da desigualdade em cada unidade federativa, assim como a robustez dos resultados econométricos. As séries dessas variáveis foram calculadas a partir das respostas à Pesquisa Nacional por Amostras de Domicílios PNAD/IBGE6.

A Tabela 8 que se encontra no Anexo $A$ apresenta as principais estatísticas descritivas dos dados. Os valores observados para ambos os índices de desigualdade indicaram o Estado de Roraima como o menos desigual no ano de 1983, no entanto, divergiram no entendimento do estado cuja concentração de renda se deu de forma mais proeminente, destacando o Estado do Piauí em 1990 no cálculo do índice de Gini e o Rio de Janeiro em 1989, para o índice de Theil. Quando se considera a média do índice de Gini $(0,564)$ nota-se que a maioria dos estados

\footnotetext{
3 Para maiores informações ver Greene (2012).

${ }^{4}$ Os valores monetários da renda domiciliar per capita média encontram-se expressos em termos dos preços vigentes no ano de 2009.

5 "Mede o grau de desigualdade na distribuição da renda domiciliar per capita entre os indivíduos. É o logaritmo da razão entre as médias aritmética e geométrica das rendas individuais, sendo nulo quando não existir desigualdade de renda entre os indivíduos e tendente ao infinito quando a desigualdade tender ao máximo" (IPEADATA).

${ }^{6}$ Como a PNAD não dispõe de informações para os anos de 1991, 1994 e 2000, optou-se por inserir a média aritmética entre os anos anterior e posterior aos dados faltantes.
} 
possui valores superiores a este, enquanto o mesmo não ocorre com o índice de Theil.

A variável de renda obteve como média a importância de RS 490,00 ao longo desse período. O máximo valor foi registrado no ano de 1990 no Estado de São Paulo e o mínimo no Amazonas em 1991. O elevado desvio padrão revela a gravidade da desigualdade de renda no país.

A título de ilustração, os Gráficos 1 e 2 apresentam a evolução da desigualdade de renda captada pelos índices de Gini e de Theil durante todo o período analisado. Observa-se, à primeira vista, o formato de $\mathrm{U}$ invertido para ambos os indicadores.

Gráfico 1. Índice de Gini para os estados brasileiros (1981-2009)

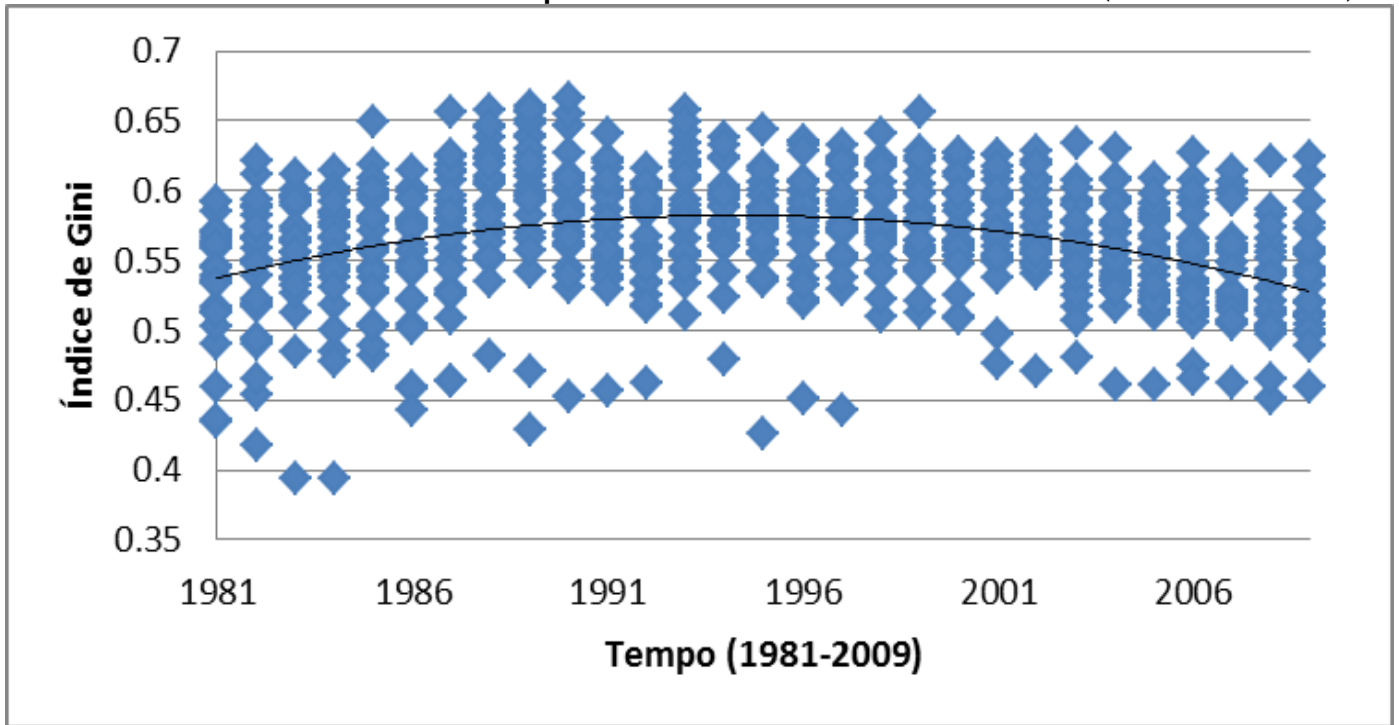

Fonte: Ipeadata. Elaboração dos autores.

Gráfico 2. Índice de Theil para os estados brasileiros (1981-2009)

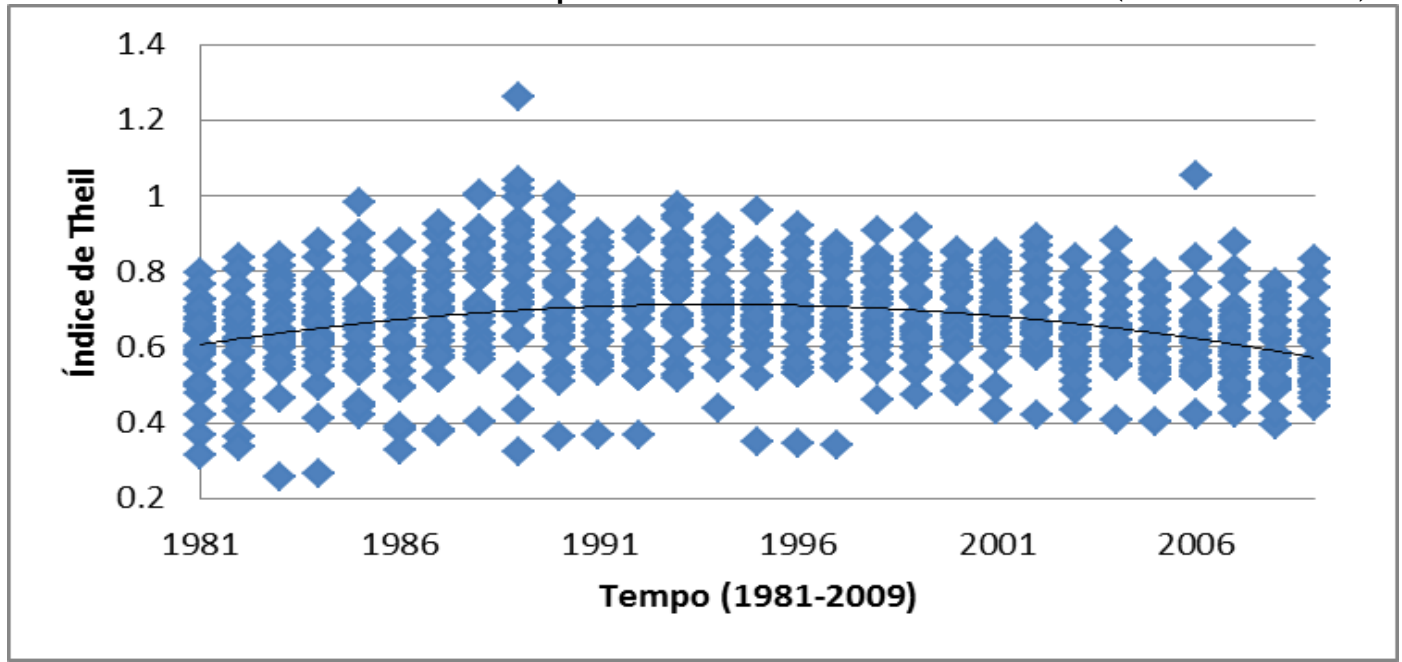

Fonte: Ipeadata. Elaboração dos autores. 
Considerando a relação entre os indicadores de desigualdade e a variável de renda para os estados brasileiros no período abordado, nota-se, aparentemente, a configuração de um $U$ normal, independente do indicador de desigualdade utilizado, e não de um $U$ invertido como pressupõe a hipótese de Simon Kuznets (1955). 
Gráfico 3. Relação entre o índice de Gini e a renda domiciliar per capita média para os estados brasileiros (1981-2009)

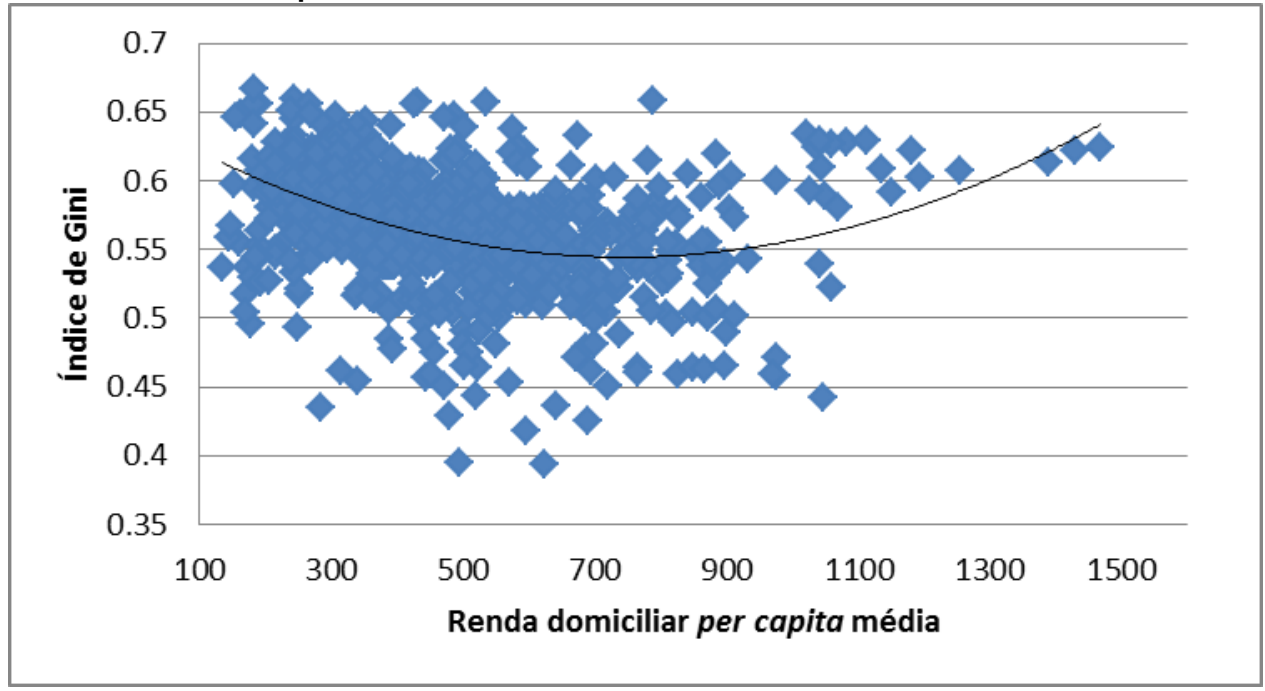

Fonte: Ipeadata. Elaboração dos autores.

Gráfico 4. Relação entre o índice de Theil e a renda domiciliar per capita média para os estados brasileiros (1981-2009)

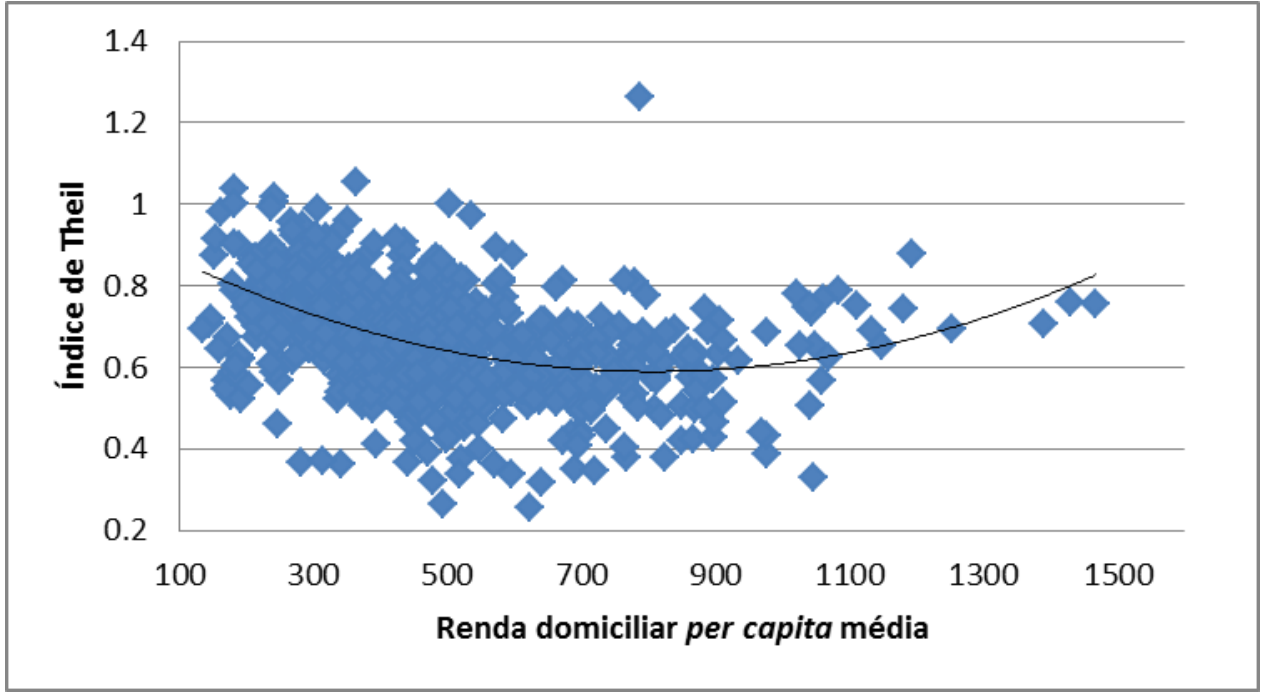

Fonte: Ipeadata. Elaboração dos autores.

Faz-se oportuno ressaltar que a média da renda das unidades consideradas é influenciada pelas unidades da federação que obtêm níveis mais elevados de renda. O mesmo ocorre quando se observa os indicadores de desigualdade de renda, sobretudo o índice de Theil, que apresenta valores muito extremados, podendo levar a conclusões errôneas. Para tanto, a separação dos estados em macrorregiões foi 
Reexaminando a Curva de Kuznets: evidências para o Brasil no período de 1981-2009

adotada como critério para algumas estimações com o intuito de se testar com maior precisão a hipótese de Kuznets. 


\section{Análise das evidências empíricas}

Esta seção apresenta os valores obtidos nas estimações sugeridas. As tabelas a seguir exibem os resultados para ambos os índices (Gini e Theil) e são ordenadas segundo as subdivisões referentes ao tipo de modelo estimado, aos grupos de macrorregiões brasileiras e aos períodos considerados.

Serão relatados alternadamente os resultados do modelo $1 \mathrm{e}$, posteriormente, os referentes ao modelo 2 para cada região aqui considerada. Vale lembrar que, para a caracterização do $U$ invertido, tem-se como hipótese: $H_{0}: \beta_{1}>0, \beta_{2}<0$ e, adicionalmente para 0 modelo $2, \beta_{3}>0$. Considera-se o nível de significância de $5 \%$ para todos os parâmetros estimados, assim como para os valores dos testes de Hausman verificados, que indicam a melhor estimação entre os modelos de dados em painel.

As Tabelas de 1 a 4 a seguir apresentam os resultados verificados para os modelos 1 e 2 de todos os estados da federação para todos os períodos avaliados.

Tabela 1. Resultados das regressões do Modelo 1 para os estados da federação (Índice de Gini)

\begin{tabular}{c|c|c|c|c|c|c|c|c|c}
\hline Período & \multicolumn{3}{|c|}{$1981-2009$} & \multicolumn{3}{c|}{$1981-1994$} & \multicolumn{3}{|c}{$1995-2009$} \\
\hline $\begin{array}{c}\text { Regressor } \\
(\sigma)\end{array}$ & EF & EA & PD & EF & EA & PD & EF & EA & PD \\
\hline $\mathrm{Y}$ & 0.619 & $0.527^{*}$ & 0.484 & $-0.894^{*}$ & -0.532 & 0.447 & 0.531 & -0.049 & 0.460 \\
& $(2.01)$ & $(3.06)$ & $(1.76)$ & $(3.20)$ & $(1.89)$ & $(1.53)$ & $(0.84)$ & $(-0.13)$ & $(0.81)$ \\
$Y^{2}$ & $-0.054^{*}$ & $-0.047^{*}$ & -0.364 & $-0.067^{*}$ & -0.040 & -0.035 & -0.055 & -0.005 & -0.024 \\
& $(-2.13)$ & $(-3.29)$ & $(-1.66)$ & $(-2.87)$ & $(-1.74)$ & $(-1.50)$ & $(-1.07)$ & $(-0.19)$ & $(-0.56)$ \\
$\beta_{0}$ & $-2.312^{*}$ & $-2.027^{*}$ & -0.000 & $-3.507^{*}$ & $-2.283^{*}$ & $0.006^{*}$ & -1.726 & -0.049 & $-0.007^{*}$ \\
& $(-2.51)$ & $(-3.90)$ & $(-0.40)$ & $(-4.21)$ & $(-2.72)$ & $(2.08)$ & $(-0.90)$ & $(-0.04)$ & $(-3.47)$ \\
$R^{2}$ & 0.0462 & 0.0457 & 0.0201 & 0.0762 & 0.0740 & 0.0121 & 0.1819 & 0.1737 & 0.1166 \\
Obs: & 754 & 754 & 728 & 364 & 364 & 338 & 390 & 390 & 364 \\
$U$ & Não & Sim & Não & Não & Não & Não & Não & Não & Não \\
Invertido? & & & & & & & & & \\
\hline
\end{tabular}

Fonte: Dados da pesquisa. Elaboração dos autores.

Nota: * Estatisticamente significante a $5 \%$.

Tabela 2: Resultados das regressões do Modelo 1 para os estados da federação para (Índice de Theil)

\begin{tabular}{c|c|c|c|c|c|c|c|c|c}
\hline Período & \multicolumn{3}{|c|}{$1981-2009$} & \multicolumn{3}{c|}{$1981-1994$} & \multicolumn{3}{c}{$1995-2009$} \\
\hline $\begin{array}{c}\text { Regressor } \\
(\sigma)\end{array}$ & EF & EA & PD & EF & EA & PD & EF & EA & PD \\
\hline Y & 1.217 & $1.026^{*}$ & 0.951 & $1.484^{*}$ & 0.578 & 0.610 & 0.953 & -0.307 & 2.534 \\
\cline { 3 - 8 }
\end{tabular}


Reexaminando a Curva de Kuznets: evidências para o Brasil no período de 1981-2009

\begin{tabular}{c|ccc|ccc|ccc}
\hline \multirow{2}{*}{$Y^{2}$} & $(1.63)$ & $(2.63)$ & $(1.22)$ & $(2.08)$ & $(0.81)$ & $(0.74)$ & $(0.70)$ & $(-0.37)$ & $(1.26)$ \\
& -0.108 & $-0.093^{*}$ & -0.066 & -0.106 & -0.042 & -0.044 & -0.102 & 0.002 & -0.165 \\
& $(-1.75)$ & $(-2.88)$ & $(-1.06)$ & $(-1.80)$ & $(-0.71)$ & $(-0.68)$ & $(-0.91)$ & $(0.04)$ & $(-1.04)$ \\
$\beta_{0}$ & -3.804 & $-3.178^{*}$ & -0.002 & $-5.446^{*}$ & -2.334 & 0.013 & -2.396 & 1.356 & $-0.018^{*}$ \\
& $(-1.68)$ & $(-2.70)$ & $(-0.51)$ & $(-2.54)$ & $(-1.11)$ & $(1.57)$ & $(-0.58)$ & $(0.53)$ & $(-3.48)$ \\
$R^{2}$ & 0.0321 & 0.0313 & 0.0218 & 0.0519 & 0.0514 & 0.0065 & 0.1217 & 0.1151 & 0.1575 \\
Obs: & 754 & 754 & 728 & 364 & 364 & 338 & 390 & 390 & 364 \\
U & Não & Sim & Não & Não & Não & Não & Não & Não & Não \\
invertido? & & & & & & & & & \\
\hline
\end{tabular}

Fonte: Dados da pesquisa. Elaboração dos autores. 
Tabela 3: Resultados das regressões do Modelo 2 para os estados da federação (Índice de Gini)

\begin{tabular}{|c|c|c|c|c|c|c|c|c|c|}
\hline Período & \multicolumn{3}{|c|}{$1981-2009$} & \multicolumn{3}{|c|}{$1981-1994$} & \multicolumn{3}{|c|}{ 1995-2009 } \\
\hline $\begin{array}{c}\text { Regress } \\
\text { or } \\
(\sigma)\end{array}$ & $\mathrm{EF}$ & EA & PD & EF & EA & PD & EF & EA & PD \\
\hline $\mathrm{Y}$ & $\begin{array}{l}6.527 \\
(1.90)\end{array}$ & $\begin{array}{l}7.412^{*} \\
(4.12)\end{array}$ & $\begin{array}{l}-6.131 \\
(-1.77)\end{array}$ & $\begin{array}{l}-0.565 \\
(-0.24)\end{array}$ & $\begin{array}{l}0.617 \\
(0.23)\end{array}$ & $\begin{array}{l}-5.752 \\
(-1.39)\end{array}$ & $\begin{array}{c}17.876 \\
* \\
(3.26)\end{array}$ & $\begin{array}{c}19.141^{*} \\
(4.90)\end{array}$ & $\begin{array}{l}3.862 \\
(0.52)\end{array}$ \\
\hline$Y^{2}$ & $\begin{array}{l}-1.034 \\
(-1.81)\end{array}$ & $\begin{array}{l}-1.189 * \\
(-3.99)\end{array}$ & $\begin{array}{l}1.055 \\
(1.84)\end{array}$ & $\begin{array}{l}0.133 \\
(0.33)\end{array}$ & $\begin{array}{l}-0.086 \\
(-0.19)\end{array}$ & $\begin{array}{l}0.995 \\
(1.44)\end{array}$ & $\begin{array}{c}- \\
2.831 * \\
(-3.27)\end{array}$ & $\begin{array}{c}-3.059 * \\
(-4.93)\end{array}$ & $\begin{array}{l}-0.589 \\
(-0.50)\end{array}$ \\
\hline$Y^{a}$ & $\begin{array}{l}0.053 \\
(1.71)\end{array}$ & $\begin{array}{c}0.062 * \\
(3.84)\end{array}$ & $\begin{array}{l}-0.059 \\
(-1.90)\end{array}$ & $\begin{array}{l}-0.009 \\
(-0.39)\end{array}$ & $\begin{array}{l}0.004 \\
(0.16)\end{array}$ & $\begin{array}{l}-0.056 \\
(-1.49)\end{array}$ & $\begin{array}{l}0.148^{*} \\
(3.29)\end{array}$ & $\begin{array}{l}0.162 * \\
(4.95)\end{array}$ & $\begin{array}{l}0.031 \\
(0.50)\end{array}$ \\
\hline$\tau$ & $\begin{array}{l}-0.000 \\
(-0.36)\end{array}$ & $\begin{array}{l}-0.000 \\
(0.555)\end{array}$ & $\begin{array}{c}- \\
0.000 * \\
(-3.95)\end{array}$ & $\begin{array}{l}0.006 * \\
(5.35)\end{array}$ & $\begin{array}{c}0.006^{*} \\
(5.62)\end{array}$ & $\begin{array}{l}-0.001 \\
(-1.73)\end{array}$ & $\begin{array}{c}- \\
0.005^{*} \\
(-3.71)\end{array}$ & $\begin{array}{l}-0.005^{*} \\
(-9.09)\end{array}$ & $\begin{array}{l}-0.002 \% \\
(-3.95)\end{array}$ \\
\hline$\beta_{0}$ & $\begin{array}{c}- \\
13.621 \\
(-1.92)\end{array}$ & $\begin{array}{c}- \\
15.391^{*} \\
(-0.59)\end{array}$ & $\begin{array}{l}1.729 * \\
(3.95)\end{array}$ & $\begin{array}{c}- \\
12.138 * \\
(-2.52)\end{array}$ & $\begin{array}{c}- \\
14.850 * \\
(-2.72)\end{array}$ & $\begin{array}{l}2.569 \\
(1.74)\end{array}$ & $\begin{array}{c}- \\
26.457 \\
(-1.94)\end{array}$ & $\begin{array}{c}-28.465^{*} \\
(-3.34)\end{array}$ & $\begin{array}{c}4.048^{*} \\
(3.95)\end{array}$ \\
\hline$R^{2}$ & 0.0588 & 0.0578 & 0.0530 & 0.2524 & 0.2436 & 0.0327 & 0.4139 & 0.4105 & 0.1604 \\
\hline Obs: & 754 & 754 & 728 & 364 & 364 & 338 & 390 & 390 & 364 \\
\hline $\begin{array}{c}\mathrm{U} \\
\text { invertido } \\
? \\
\end{array}$ & Não & Sim & Não & Não & Não & Não & Não & Sim & Não \\
\hline
\end{tabular}

Fonte: Dados da pesquisa. Elaboração dos autores.

Tabela 4: Resultados das regressões do Modelo 2 para os estados da federação (Índice de Theil)

\begin{tabular}{c|ccc|c|c|c|c|c|c}
\hline Período & \multicolumn{3}{|c|}{$1981-2009$} & \multicolumn{3}{c|}{$1981-1994$} & \multicolumn{3}{c}{$1995-2009$} \\
$\begin{array}{c}\text { Regressor } \\
(\sigma)\end{array}$ & EF & EA & PD & EF & EA & PD & EF & EA & PD \\
\hline$Y$ & 13.105 & $15.331^{*}$ & - & -4.005 & -0.183 & -8.705 & $39.846^{*}$ & $42.747^{*}$ & 25.990 \\
& $(1.50)$ & $(3.62)$ & 11.343 & $(-0.60)$ & $(-0.02)$ & $(-0.71)$ & $(3.11)$ & $(4.59)$ & $(1.01)$ \\
$Y^{2}$ & & & $(-1.12)$ & & & & & & \\
& -2.076 & $-2.467^{*}$ & 1.962 & 0.711 & 0.010 & 1.503 & $-6.326^{*}$ & $-6.852^{*}$ & -3.993 \\
$Y^{a}$ & $(-1.44)$ & $(-3.51)$ & $(1.17)$ & $(0.63)$ & $(0.01)$ & $(0.74)$ & $(-3.13)$ & $(-4.65)$ & $(-0.96)$ \\
& 0.108 & $0.130^{*}$ & -0.111 & -0.040 & 0.000 & -0.085 & $0.332^{*}$ & $0.363^{*}$ & 0.208 \\
$\tau$ & $(1.37)$ & $(3.38)$ & $(-1.19)$ & $(-0.64)$ & $(0.01)$ & $(-0.75)$ & $(3.16)$ & $(4.71)$ & $(0.94)$ \\
& -0.000 & -0.000 & $-0.00^{*}$ & $0.013^{*}$ & $0.015^{*}$ & -0.002 & $-0.011^{*}$ & $-0.011^{*}$ & $-0.005^{*}$ \\
$\beta_{0}$ & $(-0.43)$ & $(-0.47)$ & $(-2.93)$ & $(4.86)$ & $(8.55)$ & $(-1.04)$ & $(-3.08)$ & $(-7.21)$ & $(-5.26)$ \\
& - & $-30.96^{*}$ & $3.68^{*}$ & - & - & 4.512 & - & - & $10.299^{*}$ \\
& 26.112 & $(-3.62)$ & $(2.92)$ & 21.010 & $29.737^{*}$ & $(1.05)$ & 60.109 & $65.717^{*}$ & $(5.26)$ \\
$R^{2}$ & $(-1.45)$ & & & $(-1.68)$ & $(-1.80)$ & & $(-1.86)$ & $(-3.23)$ & \\
Obs: & 0.0408 & 0.0396 & 0.0382 & 0.1879 & 0.1756 & 0.0124 & 0.2883 & 0.2855 & 0.1961 \\
U & 754 & 754 & 728 & 364 & 364 & 338 & 390 & 390 & 364 \\
invertido? & Não & Sim & Não & Não & Não & Não & Sim & Sim & Não \\
\hline
\end{tabular}

Fonte: Dados da pesquisa. Elaboração dos autores. 
De acordo com os resultados apresentados, apenas o modelo de EA, no período entre 1981 a 2009 nas tabelas 4 e 5, indicou a formação da curva de Kuznets. No entanto, ao considerar que, nas tabelas de 4 a 7, os resultados do teste de Hausman selecionaram o modelo de EA como melhor estimativa, verifica-se a não corroboração da hipótese de Kuznets para todo o Brasil em todos os períodos, para ambos os modelos sugeridos. Nota-se ainda, nas tabelas 6 e 7, que para 0 período posterior ao Plano Real, a formação do $U$ invertido é seguida por uma nova tendência de ascensão da desigualdade, captada pelos valores positivos dos coeficientes de $Y^{3}$.

A respeito dos coeficientes da tendência, quando estes são significantes, seus valores se aproximam de zero, indicando que não houve mudança significativa na estrutura da economia brasileira ao longo do período considerado.

As estimativas apresentam uma considerável robustez devido aos resultados semelhantes obtidos pelos índices de Gini e de Theil. E, pode-se dizer que os baixos valores dos coeficientes de determinação encontrados deixam claro que o crescimento econômico, aqui mensurado pela renda domiciliar per capita média, não é suficiente para explicar a desigualdade, sugerindo a inclusão de variáveis de controle nos modelos dos futuros trabalhos a serem realizados sobre esta temática.

\section{Considerações Finais}

O presente trabalho investigou a hipótese da Curva de Kuznets com o intuito de verificar se existe uma relação de "U invertido" entre a desigualdade de renda e crescimento econômico no Brasil ao longo dos anos entre 1981 a 2009. Em busca de uma resposta à indagação de Kuznets (1955) acerca da trajetória da desigualdade de renda nos países em processo de desenvolvimento, este estudo propôs uma reflexão para além da análise econométrica, levando-se em conta o contexto da economia brasileira entre os anos de 1981 a 2009.

Como metodologia, dois modelos foram sugeridos: a forma quadrática usual de Ahluwalia (1976 b) e a cúbica, de List e Gallet (1999), com o acréscimo da variável de tendência, objetivando captar uma possível retomada da ascensão da desigualdade, assim como 
eventuais mudanças estruturais na economia. A análise compreendeu os Estados da Federação e o Distrito Federal, no período entre 1981 a 2009. Utilizando as técnicas de EF, EA e PD, as regressões foram estimadas para diferentes períodos e macrorregiões, objetivando-se captar os efeitos específicos dos distintos contextos.

A escolha de dois indicadores de desigualdade de renda - Índice de Gini e Índice de Theil - e a linearização das variáveis teve como intuito prover maior robustez aos modelos estimados. Pode-se dizer que tal objetivo foi auferido, visto que as estimações para ambos os índices, em sua maioria, convergiram para o mesmo resultado.

Considerando o baixo poder explicativo desses modelos, é oportuno o acréscimo de controles que contemplem características físicas e econômicas das regiões. Sugere-se, portanto, a inclusão de outras variáveis explicativas e a utilização de variáveis instrumentais que podem vir a contribuir para estudos futuros que objetivem testar a hipótese de Kuznets.

Muitos fatores podem ter contribuído para a recente retomada da elevação da desigualdade. O período aqui considerado perpassa por significativas transformações no seio econômico, político e social do Brasil. A começar pela década de 1980, período conturbado em que o sistema político transitava em direção à retomada da democracia, a economia brasileira passava pela então denominada "Década Perdida". Diversos planos econômicos foram elaborados para o combate à inflação. Ao mesmo tempo, a concentração de renda exacerbava as desigualdades já existentes. O Plano Cruzado e o Plano Verão foram exemplos de políticas públicas que provocaram um aumento da desigualdade de renda no país.

A década de 1990 gestava um novo modelo de crescimento, instituído a partir de uma concepção liberal-internacionalizante de progresso econômico e social. O Plano Real, estabelecido na primeira metade da década, foi eficaz no controle da inflação e eliminou o imposto inflacionário que deteriorava a renda das parcelas mais pobres da população, realizando um ajuste na economia brasileira. No entanto, não existe um consenso acerca dos efeitos da abertura econômica e da liberalização dos mercados sobre a desigualdade de renda.

Os últimos anos investigados foram marcados pelas políticas de estabilização monetária, de transferências de renda e de valorização do 
salário mínimo adotadas pelo governo, contribuindo para a retirada de grande parte da população das condições de miséria e extrema pobreza. Tal fato se verifica pela redução da concentração de renda, mensurada a partir dos índices de Theil e de Gini. No entanto, faz-se oportuno questionar o quanto, de fato, essas medidas são sustentáveis e capazes de quebrar o ciclo intergeracional de desigualdade existente.

Os direitos sociais universais à saúde, educação de qualidade e previdência social, assim como a responsabilidade do Estado de provêlos, foram consagrados na Constituição Federal de 1988. Um dos méritos dos governos de FHC e Lula foi a universalização destes direitos a toda sociedade. No entanto, sabe-se que a população brasileira passa por um momento de transição demográfica, em que a taxa de crescimento das crianças se reduziu significativamente, facilitando o acesso a esses serviços. Não obstante, a promoção desses se dá em detrimento da qualidade, reforçando o processo de concentração de renda e elevação das desigualdades.

A transição demográfica, processo social que possui sua originalidade no Brasil devido à rapidez que vem modificando a estrutura etária da população, pode ser considerada causa e efeito das transformações sociais e econômicas, interferindo em diversos aspectos da economia brasileira. O processo de reestruturação do mercado de trabalho é um exemplo claro desse fenômeno, de forma que as reduzidas taxas de desemprego verificadas atualmente são um reflexo direto da queda nas taxas de crescimento populacional.

A conjuntura demográfica do Brasil contemporâneo é favorável e deve ser aproveitada tendo como intuito ampliar a capacidade de mobilidade e inclusão social da maior parte da população. Portanto, qualquer compromisso com a mitigação das desigualdades deve levar em conta a construção de uma agenda social eficiente, que saiba gerir os recursos de acordo com o momento demográfico em que a população se encontra.

O bônus demográfico brasileiro deve ser desfrutado de maneira a incrementar os investimentos em capital humano na população jovem, para que estes, no futuro, possam ser responsáveis pelos seus próprios destinos e não fiquem à mercê das transferências de renda concedidas pelo governo. Logo, faz-se necessário que as políticas previdenciárias, a médio e longo prazo, sejam pensadas e articuladas com as medidas 
direcionadas para os jovens contemporâneos, criando as condições para sua mobilidade e inclusão social futura.

Conclui-se que, em consonância com Luna e Klein (2009), que embora as forças do mercado, por meio do crescimento, contribuam para a melhoria dos indicadores de concentração de renda, estas não são capazes de sustentá-las sem a existência de políticas de redistribuição de renda. Embora os indicadores de desigualdade venham sugerindo melhorias no processo de redistribuição de renda, apenas políticas públicas efetivas no atendimento de serviços sociais fundamentais, como educação e saúde de qualidade, saneamento e habitação, concomitantes às políticas compensatórias de distribuição de renda, evitarão que um novo ciclo de crescimento seja apropriado apenas por um pequeno grupo da população. 


\section{REFERÊNCIAS}

ACEMOGLU, D; JAMES, A. R. The Political Economy of the Kuznets Curve. Review of Development Economics, 6 (2), 183-203, 2002.

ADELMAN, I; MORRIS, C. T. Economic growth and social equity in developing

Countries. Stanford University Press: Stanford, CA, 1973

AHLUWALIA, MONTEK S. Income distribution and development: Some stylized facts, American Economic Review, Papers and Proceedings 66, n. 2, 128-135, 1976 a.

AHLUWALIA, MONTEK S., Inequality, poverty and development. Journal of Development Studies, v. 3, p. 307-342,1976 b.

ALESINA, A.; RODRIK, D. Distributive politics and economic growth. The Quartely Journal of Economics, Vol. 119, n. 2, 1994.

ALESINA, A.; PEROTTI, R. Income distribution, political instability and investment. European Economic Review,v. 40, n. 6, 1996.

AMOS, O., "Unbalanced Regional Growth and Regional Income Inequality in the Latter Stages of Development," Regional Science and Urban Economics 18, 549-66, 1988.

ANAND, S.; KANBUR, S. M. R. The Kuznets process and the inequality development relationship. Journal of Development Economics, n. 40, p. 25-52, 1993.

BAGOLIN, I. P.; GABE, J.; RIBEIRO, E. P. Crescimento e desigualdade no Rio Grande do Sul: uma revisão da curva de Kuznets para os municípios gaúchos (1970-1991). In: Econtro de Economia Gaúcha, 2., 2004, Porto Alegre, RS. Porto Alegre: Fee, 2004.

BARROS, L. C.; GOMES, F. A. R. Desigualdade e Desenvolvimento: a hipótese de Kuznets é valida para os municípios brasileiros? Ibmec SP 
Working Paper, n. 28, 2007. Disponível em $<$ www.ibmecsp.edu.br/pesquisa/download.php?recid $=3101>$. Acesso em 13 mar 2008.

BÊRNI, D. A.; MARQUETTI, A.; KLOECKNER, R. A desigualdade econômica do Rio Grande do Sul: primeiras investigações sobre a curva de Kuznets. In: Encontro de Economia Gaúcha, 1, 2002, Porto Alegre, RS. Anais... Porto Alegre: FEE, 2002.

BOURGUIGNON, F., MORRISON, C.. Income distribution, development and foreign trade: a cross-sectional analysis. European Economic Review $34,1113-1132,1990$

CAMPANO, F., SALVATORE, D. Economic development, income inequality, and Kuznets' U-shaped hypothesis. Journal of Policy Modeling 10 _2., 265-280, 1988.

BRASIL. Constituição (1988). Constituição da República Federativa do Brasil. Preâmbulo. Brasília: Senado Federal,1988.

DAUDELIN, J. SAMY, Y. "Flipping" Kuznets: Evidence from Brazilian Municipal Level Data on the Linkage Between Income and Inequality". Desigualdades.net. Working Paper Series, n.10, 2011.

DEININGER, K.; SQUIRE, L. A new data set measuring income inequality. The World Bank Economic Review, v. 10, n. 3, 1996.

New ways of looking at the olds issues: inequality and growth. Journal of Development Economics, v. 57, n. 2, p. 259-287, 1998.

DOLLAR, D.; KRAAY, A.. Growth is good for the poor. Journal of Economic Growth, v. 7, n. 3, p. 195-225, 2002.

EASTERLY, W.. Life during growth: international evidence on quality of life and per capita income. Journal of Economic Growth, n. 4, 1999. 
GALOR, O., D. TSIDDON. Technological progress, mobility, and economic growth. American Economic Review, v. 87, p.363-382. 1997.

GREENE William, H. Econometric Analysis. 7. ed. Prentice Hall,. 1198p, 2012.

INSTITUTO DE PESQUISA ECONÔMICA APLICADA. Disponível em $<$ lpeadata.gov.br>. Acesso em 18 fev. 2013.

INSTITUTO DE PESQUISA ECONÔMICA APLICADA. Políticas Sociais: acompanhamento e análise, Brasília, n. 20, p. 197-247, 2012.

JACINTO, P. A.; TEJADA, C. A. O. Desigualdade de renda e crescimento econômico nos municípios da região nordeste do Brasil: O que os dados têm a dizer? In: Encontro de Economia da Anpec, 32., 2004, João Pessoa, PB. Anais... Niterói: Anpe, 2004.

KANBUR, R. Does Kuznets Still Matter? paper written for a Festschrift in honor of Montek Ahluwalia, September, 2011 , revised version published in S. Kochhar (ed.) Policy Making for Indian Planning, 115-128, Academic Foundation Press, 2012.

KUZNETS, S.. Economic Growth and Income Inequality. American Economic Review, v.45, n.1. 1955.

Quantitative Aspects of the Economic Growth of Nations: VIII, Distribution of Income By Size, Economic Development and Cultural Change, January, Part 2, 1-80, 1963.

LEWIS, W. Arthur. Economic Development with Unlimited Supplies of Labor, Manchester School of Economic and Social Studies, Vol. 22, pp. 139-91, 1954.

LUNA, F. V., KLEIN, H.S. Desigualdade e indicadores sociais no Brasil. In: Schwartzman, Luisa Farah et. al. (Org.). O sociólogo e as Políticas Públicas: Ensaios em Homenagem a Simon Schwartzman. Rio de Janeiro: FGV, 97-116, 2009. 
MILANOVIC, B.. Poverty, inequality and social policy in transition economies, Transition Economics Division, Research Paper 9. Washington, DC, The World Bank. 1995.

ONU-Habitat. Estado de las ciudades de América Latina y El Caribe 2012. Rumbo a una nueva transición urbana. Copyright: Programa de las Naciones Unidas para los Asentamientos Humanos, Nairobi/México?: ONU Habitat, Agosto de 2012 Disponível em: $<$ http://www.onu.org.br/onu-lanca-relatorio-inedito-sobre-cidadeslatino-americanas $>$. Acesso em: 15 jan. 2013.

PAPANEK, G., KYN, O. The effect on income distribution of development, the growth rate andeconomic strategy. Journal of Development Economics 23, 55-65, 1986

RAVALLION, M. Growth and poverty: evidence for developing countries in the 1980s. Economics Letters, Elsevier, v. 48, p. 411-417, 1995.

RAVALLION, M.; CHEN, S. What can new survey data tell us about recent changes in distribution and poverty? World Bank Economic Review, Oxford University Press, v. 1 1, n. 2, p. 357-382, 1997.

SALAMA, Pierre; DESTREMAU, Blandine. O tamanho da pobreza. Economia política da distribuição de renda. Rio de Janeiro: Editora Garamond, 1999.

SALVATO, A. et al. Crescimento e desigualdade: evidências da Curva de Kuznets para os municípios de Minas Gerais - 1991/2000. Working Paper. Belo Horizonte: IBMEC MG, n. 33, 2006.

LINHARES F.; FERREIRA R, T.; IRFFI, G. D.; MACEDO, C. M. B. A hipótese de Kuznets e mudanças na relação entre desigualdade e crescimento de renda no Brasil. IPEA. Pesquisa e Planejamento Econômico - PPE. Volume 42. número 3. Dez/2012. Disponível em: $<$ http://ppe.ipea.gov.br/index.php/ppe/issue/view/129>. Acesso em: 15 maio 2013. 
LIST, J. A.; GALLET, C. A. The Kuznets curve: what happens after the inverted-U. Review of Development Economics, Ano III, p. 200-206, fev. 1999.

TAQUES, F. H., C. C. MAZZUTI T. P. Qual a Relação entre Desigualdade de Renda e Nível de Renda Per Capita? Testando a Hipótese de Kuznets para as Unidades Federativas Brasileiras. Ipea. Planejamento e Políticas Públicas. Número 35. Jul/Dez 2010. 161-186. Disponível em: <http://www.ipea.gov.br/ppp/index.php/PPP/issue/view/29/showToc> . Acesso em: 15 maio 2013.

TRIBBLE, R., "The Kuznets-Lewis Process within the Context of Race and Class in the US Economy," International Advances in Economic Research, 2, 151-64, 1996.

WOOLDRIDGE, Jeffrey M. Econometric Analysis of Cross Section and Panel Data .Cambridge, Massachussets; London, England: MIT Press, 2002.

Recebido em 05/10/2014

Aprovado em 19/04/2016

Sobre os autores

Francisco José Silva Tabosa

Economista. Dr. Professor do DEA/MAER/UFC.

E-mail franzetabosa@ufc.br

Jair do Amaral Filho

Economista. Dr. Professor do CAEN/UFC.

E-mail: amarelojair@gmail.com

Uyara de Salles Gomide

Economista. Mestre pelo CAEN/UFC.

E-mail: amarelojair@gmail.com 


\section{ANEXO A}

Tabela 8. Estatística descritiva das variáveis

\begin{tabular}{lccc}
\hline Estatísticas & \multicolumn{3}{c}{ Variáveis } \\
\cline { 2 - 4 } & Gini & Theil & Y \\
\hline Média & 0,564 & 0,668 & 490,00 \\
Máximo & 0,666 & 1,263 & $1.468,05$ \\
Mínimo & 0,393 & 0,254 & 134,72 \\
Desvio- & 0,043 & 0,130 & 210,78 \\
padrão & & & \\
Observações & 754 & 754 & 754 \\
\hline
\end{tabular}

Fonte: Dados da pesquisa. Elaboração dos autores.

\section{ANEXO B}

Tabela 9. Resultados dos testes de Hausman para o índice de Gini de acordo com as regiões e modelos considerados

\begin{tabular}{cccc|ccc}
\hline & \multicolumn{3}{c}{ Modelo 1 } & \multicolumn{3}{c}{ Modelo 2 } \\
\cline { 2 - 7 } (Região\Período) & $(81-09)$ & $(81-94)$ & $(95-09)$ & $(81-09)$ & $(81-94)$ & $(95-09)$ \\
\hline Todos os Estados & 0.0044 & 0.0000 & 0.0000 & 0.0040 & 0.0000 & 0.0019 \\
\hline Grupo A & 0.0001 & 0.0000 & 0.9118 & 0.1719 & 0.0000 & 0.0193 \\
\hline Grupo B & 0.0223 & 0.0091 & 0.0000 & 0.0054 & 0.0342 & 0.0000 \\
\hline
\end{tabular}

Fonte: Dados da pesquisa. Elaboração dos autores.

Tabela 10. Resultados dos testes de Hausman para o índice de Theil de acordo com as regiões e modelos considerados

\begin{tabular}{cccc|ccc}
\hline & \multicolumn{3}{c}{ Modelo 1 } & \multicolumn{3}{c}{ Modelo 2 } \\
\cline { 2 - 7 } (Região\Período) & $(81-09)$ & $(81-94)$ & $(95-09)$ & $(81-09)$ & $(81-94)$ & $(95-09)$ \\
\hline Todos os Estados & 0.0037 & 0.0000 & 0.0003 & 0.0049 & 0.0000 & 0.0085 \\
\hline Grupo A & 0.0000 & 0.0407 & 0.3438 & 0.0008 & 0.0000 & 0.0039 \\
\hline Grupo B & 0.0001 & 0.0849 & 0.0000 & 0.1766 & 0.0708 & 0.0026 \\
\hline
\end{tabular}

Fonte: Dados da pesquisa. Elaboração dos autores. 